\title{
MILITARY SERVICE AND PUBLIC SECTOR EMPLOYMENT: BIRTHDATES CALLED IN THE VIETNAM DRAFT LOTTERIES APPEAR EXCESSIVELY IN THE POPULATION OF CIVILIAN U.S. FEDERAL PERSONNEL RECORDS
}

\author{
Tim Johnson \\ Dalton Conley \\ Working Paper 25859 \\ http://www.nber.org/papers/w25859 \\ NATIONAL BUREAU OF ECONOMIC RESEARCH \\ 1050 Massachusetts Avenue \\ Cambridge, MA 02138 \\ May 2019
}

The views expressed herein are those of the authors and do not necessarily reflect the views of the National Bureau of Economic Research.

NBER working papers are circulated for discussion and comment purposes. They have not been peerreviewed or been subject to the review by the NBER Board of Directors that accompanies official NBER publications.

(C) 2019 by Tim Johnson and Dalton Conley. All rights reserved. Short sections of text, not to exceed two paragraphs, may be quoted without explicit permission provided that full credit, including $\odot$ notice, is given to the source. 
Military Service and Public Sector Employment: Birthdates Called in the Vietnam Draft Lotteries Appear Excessively in the Population of Civilian U.S. Federal Personnel Records

Tim Johnson and Dalton Conley

NBER Working Paper No. 25859

May 2019

JEL No. J01,J45,J48

\begin{abstract}
Since at least T.H. Marshall, scholars have recognized military service as a form of sacrifice that warrants compensation from the state. Indeed, some see the very genesis of the modern welfare state as compensation for wartime sacrifice. War-widow pensions, expansion of the franchise, and subsidized higher education are all examples of rights and benefits "bestowed" in return for wartime mobilization. Similarly, in the U.S., governments have hired veterans preferentially for civilian public jobs as recompense for active military service. Although oft-overlooked, those policies appear influential: the percent of job holders identifying as veterans in the civilian U.S. executive branch exceeds the proportion in the wider population by several multiples. This century-old pattern suggests a significant means by which wartime mobilization has influenced the state. Yet efforts to understand it have struggled to rule out the possibility that those who serve in the armed forces are predisposed to work for the state in both military and civilian capacities (for example, preferring the stability of government employment). Here we rule out this possibility by examining whether birthdates randomly called for induction in the Vietnam-Era Selective Service Lotteries (VSSL) appear disproportionately in the population of non-sensitive personnel records of the civilian U.S. executive branch. We find that birthdates called for induction appear with unusually high frequency among employees who were draft eligible and at risk of induction, but not among other employees. This finding suggests a treatment effect from military service, thus dovetailing with the hypothesis that wartime mobilization has substantially and continually influenced who works in the contemporary administrative state.
\end{abstract}

\author{
Tim Johnson \\ Atkinson Graduate School of Management \\ Willamette University \\ Business School \\ 900 State Street \\ Salem, OR 97301 \\ tjohnson@willamette.edu \\ Dalton Conley \\ Department of Sociology \\ Princeton University \\ 153 Wallace Hall \\ Princeton, NJ 08544 \\ and NBER \\ dconley@princeton.edu
}




\section{Introduction}

Research argues that early states emerged from efforts to muster resources for war (Tilly, 1990), and the modern welfare state shares a similar origin. At least since T.H. Marshall (1950) identified wartime sacrifice as a basis for making claims upon the state, scholars have documented how states have extended rights, privileges, and subsidies both to encourage wartime sacrifice (Levi, 1997; Ferejohn and Rosenbluth, 2017) and compensate for it (Skocpol, 1992). Expansion of the franchise (Ferejohn and Rosenbluth, 2017), commitments to procedural fairness (Levi, 1997), pensions for war widows (Skocpol, 1992), and subsidized higher education (Mettler, 2005), to name a few examples, all reflect state efforts to elicit or reward sacrifice in times of war. Together, these mechanisms of compensation formed the modern welfare state, and their amplification in recent decades for military personnel and their families has transformed the armed forces into an enterprise with both martial and welfare purposes (Gifford, 2006).

Yet, while these policies had a foundational role in the formation of the contemporary welfare state, an often-ignored form of compensation for military sacrifice may continue to shape the contemporary state. For over a century, the U.S. federal government and various state governments have hired military veterans preferentially for public jobs (Lewis, 2013; Johnson, 2015). These policies echo similar practices in early states (Gorski, 1993; Kiser and Cai, 2003; Johnson, 2017) and research claims that these policies explain why veterans staff over $25 \%$ of U.S. executive-branch positions, despite constituting less than $10 \%$ of the U.S. population (Lewis, 2013; Lewis, 2016). Such figures suggest a marked, continual influence of wartime compensation on the state: compensation for military participation may open a path to civilian public service that veterans are particularly inclined to traverse. Indeed, evidence indicates that federal government jobs offer a wage premium (Belman and Heywood, 2004); thus, with 
preferential hiring in place, military service amounts to the assignment of a voucher giving greater access to a desirable asset.

The over-representation of military veterans among civilian employees of the government also may stem from the bundle of treatment effects that military service potentially assigns to job seekers. For instance, veterans might acclimate to the organizational structure of the military, which shares features with the civilian public bureaucracy, thus making them even more inclined to take advantage of the opportunities made available via preferential hiring (Johnson, 2015). Perhaps less optimistically, veterans might lack experience in the civilian labor market, thus impeding their efforts to find private-sector work and causing them to gravitate toward public jobs in which preferential hiring compensates for their lack of civilian labor market experience. Military service might increase patriotism, thus inspiring civilian public service after discharge. Any one of these mechanisms might underlie the effect of military service — which is indelibly linked with the receipt of federal preferential hiring benefits — on entry into public employment.

Estimating such treatment effects of military service on choice of employment sector is complicated by selection dynamics. Namely, those who serve in the armed forces might be predisposed to enter both military and civilian public service. For instance, they might prefer the comparative stability of public employment, or exhibit consistently high levels of patriotism throughout their lives, or possess a taste for working in large enterprises. That is, veterans' rates of entry into public jobs might merely reflect confounding, not the effect of military service and the eligibility for preferential hiring that is linked with it. Accordingly, to understand how the assignment of military service in the presence of preferential hiring influences entry into the executive branch and, thus, to gain insight into the way that wartime mobilization might continue to affect the state, research must eliminate possible confounders and examine how exogenous 
variation in military service affects the ranks of the civilian public service. If exogenously assigned military service does not co-vary with entry into public employment, then pre-service factors - not military service in the presence of preferential hiring — likely drive veterans toward public jobs.

Existing evidence, indeed, is inconsistent in its assessment of whether exogenous variation in military service affects the likelihood of subsequent public employment. Angrist and Chen (2011) - in a study of the late-life, labor-market experiences of men eligible for the Vietnam-Era Selective Service Lotteries (VSSL) — discovered that men's chances of working in the public sector increased with their risk of military induction thanks to having their draft number called. Green et al. (2018), on the other hand, in a study of whether the VSSL shaped draftees' political attitudes, found — in a separate sample — that the estimated effect of lotteryinduced military service on public-sector employment was smaller than its standard error-i.e. a "null" effect. Unfortunately, the different methods of each study — an instrumental variable analysis (Angrist and Chen, 2011) and an intent-to-treat analysis (Green et al. 2018) — prevent direct comparison of the studies' discrepant effect estimates. Furthermore, both studies investigate a sample, thus their divergent findings could be attributable merely to sampling error: chance sampling variation could result in data sets that, say, over- or underrepresent study participants from geographical areas with more generous (or less generous) state and local preferential hiring policies. Also, by grouping federal and lower-level employment into the same indicator of public employment, these studies mask potentially heterogeneous treatment effects that result from the systematic variation in treatment dosage across governmental jurisdictions.

The study we report in this paper overcomes these problems by studying the population of data for one level of government that is subject to a single set of preferential hiring policies. 
Specifically, the study examines whether birthdates called for induction in the Vietnam Selective Service Lotteries appear with disproportionately high frequency in the population of U.S. executive branch employees who were draft-eligible and at risk of induction. This analysis tests whether the assignment of military service increases rates of entry into federal jobs, thus shedding light on whether wartime mobilization not only played an important role in forming the state, but also continuously shaped it by populating its ranks.

\section{Methods}

The VSSL provides an exogenous source of variation in draft-eligible men's risk of military service (Berinsky and Chatfield, 2015). We parrot past studies' description of the VSSL here (see Johnson et al., 2018, fn.6). In the VSSL, the U.S. Selective Service System printed calendar dates on paper strips, placed the strips in small pods, put these pods in a receptacle, and drew pods one-by-one, assigning numbers sequentially to each month-day combination until all received numbers. These "Random Sequence Numbers" (RSNs) identified when draft-eligible men reported for military induction in the following year. Men with RSN 1 reported first, those with RSN 2 reported second, and this process continued until the RSN reached the year's “Administrative Processing Number" (APN). The APN was set before induction; it equaled 195 for the 1969 lottery, 125 in the second year, and 95 every year until 1975's final lottery. After the VSSL's first three years, numbers were assigned, but not called.

Knowing these procedures, one of the authors (TJ) filed a Freedom of Information Act request with the U.S. Office of Personnel Management (OPM) for all birthdates in the Central Personnel Data File (CPDF) - the population of official personnel data for nondefense and nonpostal agencies of the U.S. federal executive branch. These data include all employees, whether 
they work a full-time or part-time schedule, across all agencies and occupations included in the CPDF. Officials at OPM supplied a count of the total number of males and females, respectively, holding each birthdate in the monthly-archived population of personnel data from June 2011 (the first month in which full birthdates were systematically collected) to March 2016 (the mostrecent month of data available at the time of the request). Rare birthdates held by less than five employees had their counts set to zero to protect employee privacy, but no such birthdates appeared in the data studied in the analyses we report below. The time period of the data make them roughly comparable to those of Angrist and Chen (2011) and Green et al. (2018), which both reported the effect of the VSSL on later-life public employment. Given that this time period extends decades beyond the VSSL, estimates from our research design inevitably reflect patterns of retirement and mortality caused by draft-eligible men's lottery numbers. However, due to our study's aim of examining the lasting effect of military service on the administrative state, such effects should be a part of our estimation: if low lottery numbers drove individuals to work in the federal government later into their lives or to retire earlier than their colleagues with high lottery numbers, then those phenomena ultimately shaped how military service affected employment in the federal government over the long term, which is the phenomenon we seek to understand.

We subset the data to include birthdates from 1950-1956, thereby focusing exclusively on birth cohorts turning 19-years old during the VSSL, as is deemed best practice (see Angrist, 1990). To study these data, we used the research design of Conley and Heerwig (2012). We calculated $P_{S, t}$ - that is, the proportion of employees, $P$, identifying with sex, $S$, born in year, $t$, whose birthdates were assigned an RSN $\leq$ APN. If the VSSL influenced entry into civilian executive-branch employment, one would expect: $P_{M, 1950}>P_{F, 1950}, P_{M, 1951}>P_{F, 1951}$, and $P_{M, 1952}>P_{F, 1952}$. Moreover, given that no numbers were called after 1952, one would also 
expect: $P_{M, 1953} \cong P_{F, 1953}, P_{M, 1954} \cong P_{F, 1954}, P_{M, 1955} \cong P_{F, 1955}$, and $P_{M, 1956} \cong P_{F, 1956}$. As an additional counterfactual, we calculated $P_{E, t}$-that is, the theoretically-expected proportion of employees holding birthdates assigned an RSN $\leq \mathrm{APN}$, for either sex, $E$, in year, $t$, if birthdates are uniformly distributed across the year (see Conley and Heerwig, 2012). For instance, $P_{E, 1950}=195 / 365=0.5328$ because 1950 had 365 possible birthdates (it was not a leap year) and the APN equaled 195 for the 1950 birth cohort. Accordingly, we expect: $P_{M, 1950}>P_{E, 1950}$, $P_{M, 1951}>P_{E, 1951}, P_{M, 1952}>P_{E, 1952}, P_{M, 1953} \cong P_{E, 1953}, P_{M, 1954} \cong P_{E, 1954}, P_{M, 1955} \cong P_{E, 1955}$, and $P_{M, 1956} \cong P_{E, 1956}$.

\section{Results}

Results dovetail with these expectations (see Table 1). In the 1950-1952 birth cohorts, the proportion of male birthdates assigned an RSN $\leq$ APN is markedly higher than the corresponding proportions for birthdates held by females. Furthermore, in those birth cohorts, the female proportions more-closely approximate the theoretically expected proportion of birthdates assigned an RSN $\leq$ APN than do the corresponding male proportions. In the 1953-1956 birth cohorts, the proportions of male birthdates assigned an RSN $\leq$ APN differ less noticeably from the corresponding proportions for birthdates held by females. Also, the male proportions for the 1953-1956 birth cohorts approximate their corresponding, theoretically expected proportion of birthdates more closely than do the male proportions for the 1950-1952 cohorts. 
Table 1. Proportion of employee birthdates assigned lottery numbers called for induction

$$
\begin{array}{llllll}
\text { I } & \text { II } & \text { III } & \text { IV } & \text { V } & \text { VI }
\end{array}
$$

\begin{tabular}{ccccccc}
$\begin{array}{c}\text { Birth Year } \\
(t)\end{array}$ & $\begin{array}{c}\text { Proportion } \\
\text { Males } \\
(M)\end{array}$ & $\begin{array}{c}\text { Proportion } \\
\text { Females } \\
(F)\end{array}$ & $\begin{array}{c}\text { Expected } \\
\text { Proportion } \\
(\mathrm{E})\end{array}$ & $\begin{array}{c}\text { Difference } \\
\text { I }- \text { II }\end{array}$ & $\begin{array}{c}\text { Difference } \\
\text { I }- \text { III }\end{array}$ & $\begin{array}{c}\text { Difference } \\
\text { II }- \text { III }\end{array}$ \\
& & & & $D_{M F, t}=$ & $\begin{array}{c}D_{M E, t}= \\
P_{M, t}\end{array}$ & $\begin{array}{c}D_{F E, t}= \\
P_{F, t}-P_{E, t}\end{array}$ \\
& $P_{M, t}$ & $P_{F, t}$ & $P_{E, t}$ & $-P_{F, t}$ & $-P_{E, t}$ & \\
\hline 1950 & 0.5801 & 0.5449 & 0.5328 & 0.0352 & 0.0473 & 0.0121 \\
1951 & 0.3765 & 0.3422 & 0.3425 & 0.0343 & 0.0340 & -0.0003 \\
1952 & 0.2987 & 0.2570 & 0.2596 & 0.0417 & 0.0391 & -0.0026 \\
1953 & 0.2684 & 0.2559 & 0.2603 & 0.0125 & 0.0081 & -0.0044 \\
1954 & 0.2609 & 0.2669 & 0.2603 & -0.0060 & 0.0006 & 0.0066 \\
1955 & 0.2589 & 0.2595 & 0.2603 & -0.0006 & -0.0013 & -0.0008 \\
1956 & 0.2593 & 0.2592 & 0.2596 & 0.0001 & -0.0003 & -0.0004 \\
\hline
\end{tabular}

Note: Values are rounded.

These findings arise from an analysis that pools monthly-archived sets of the CPDF. Repeating the analysis on each monthly-archived CPDF does not lead to different conclusions. Figure 1 presents kernel density plots showing the distribution of $D_{M E, t}=P_{M, t}-P_{E, t}$ (upper left-hand panel), $D_{F E, t}=P_{F, t}-P_{E, t}$ (upper right-hand panel), and $D_{M F, t}=P_{M, t}-P_{F, t}$ (lower left-hand panel), by annual birth cohort, when repeating the analysis on each monthly archived version of the CPDF. Across panels, the distribution of these differences yield substantively comparable findings to the pooled results: birthdates assigned an RSN $\leq$ APN appear with disproportionately high frequency solely among draft-eligible male employees at risk of induction.

These results indicate a link between lottery numbers and civilian public employment. However, they rely heavily on the assumption that the APN cutoff value was administered 
accurately and uniformly. That said, errors in the administration of the induction call may have meant that adherence to the APN cutoff was more variable in practice than was stated in policy. Accordingly, we examined whether the substantive interpretation of the findings-namely, that the VSSL influenced the ranks of executive-branch employment—remained valid even when the APN cutoff did not figure prominently in the study design. To do so, we examined the relationship between the numerical value of RSNs assigned to federal employees and the number of employees holding the birthdates associated with those RSNs.

\section{[FIGURE 1 HERE]}

Given that low RSNs were called for induction first and given that the military's need for personnel diminished as the induction call proceeded, one would expect-if the VSSL influenced rates of federal employment - a decreasing relationship between the value of RSNs and the number of employees holding birthdates assigned those RSNs solely in data concerning men born from 1950 to 1952. However, among females as well as males in the placebo cohorts, one would expect to find a null relationship between the value of employees' lottery numbers and the number of employees holding the birthdates to which those RSNs were assigned.

\section{[FIGURE 2 HERE]}

As a first step in testing those expectations, Figure 2 shows a plot of the average number of employees holding a given lottery number and the value of that lottery number. Only among male employees born from 1950 to 1952 does a negative relationship appear between lottery numbers and the mean number of employees holding those RSNs. Moreover, among male employees born from 1950 to 1952, this negative relationship appears strong over the first 200 lottery numbers, then it flattens out thereafter. This trend reflects the fact that the highest APN 
capped the call for induction at 195: if exposure to military service influences rates of entering the federal civilian bureaucracy, one would not expect the value of lottery numbers beyond this highest APN to influence the number of federal employees holding birthdates associated with those RSNs.

\section{[FIGURE 3 HERE]}

Figure 3 shows that a similar trend appears in annual birth cohorts and it displays the discontinuity that appears at the APN cutoff in each year. That is, in each panel of Figure 3, we present raw data — from monthly archived versions of the CPDF—concerning federal employees distinguished by their sex and annual birth cohort; these data are plotted such that the value of lottery numbers appears on the horizontal axis and the raw number of employees' holding those numbers appear on the y-axis. Furthermore, in each panel, we display two smoothers estimated on, respectively, employees with lottery numbers at or below the APN and employees with lottery numbers above the APN. The three left-hand panels of Figure 3, appearing on the figure's first page, display data for male employees born from 1950 to 1952; in each panel, the number of male employees declines as the values of their lottery numbers approach the APN. Furthermore, across each of these birth cohorts, a noticeable discontinuity appears at the APN, thus indicating a drop in the number of employees holding lottery numbers greater than the APN. No other panels show this drop at the APN cutoff as vividly. Although male employees born in 1953 (on the second page of the figure) exhibit a decreasing relationship between lottery numbers and the number of employees to the left of the APN (n.b. APN=95 in 1953), ${ }^{1}$ no noteworthy

\footnotetext{
${ }^{1}$ In both this analysis and in the findings reported earlier in the main text, numbers in the VSSL seem to have had a slight effect on the executive-branch employment of men from the 1953 birth cohort. Given that 1953 was the first year in which VSSL numbers were not called for induction, it could be that men with low numbers volunteered for forms of military service they perceived as less risky in anticipation of their numbers being called. This phenomenon would have resulted in exposure to military service and the
} 
discontinuity appears at the APN's value. On the other hand, data concerning female employees born in 1951, 1954 and 1955, respectively, exhibit a pronounced discontinuity at the APN, but the smoother slightly increases as it approaches the APN value from the left, indicating that higher lottery numbers appeared more frequently in the data. Overall, in these panels concerning placebo cohorts, the data appear to exhibit a null relationship, suggesting that birthdates associated with lottery numbers at or below the APN do not appear with disproportionate frequency in the placebo cohorts. The findings indicate that a study design that puts less emphasis on the APN cutoff still provides evidence suggesting that the VSSL influenced the ranks of the civilian executive branch.

\section{Conclusion}

Efforts to mobilize martial resources sparked the development of early states (Tilly, 1990), and methods of repaying and inspiring wartime sacrifice resulted in the modern welfare state (Skocpol, 1992). Although these germinal effects of war on the state have been well studied, the continual effect of wartime mobilization on who works in the contemporary state has received less attention, even though long-standing evidence indicates unusually high rates of public-sector employment among veterans - especially in the U.S. executive branch (Lewis, 2013; Johnson, 2017). This pattern, however, could result from a predisposition that drives individuals to work for the state in both military and civilian capacities, thus calling into question the notion that wartime compensation continually affects the state by influencing who works for

acquisition of veteran status, thus remaining consistent with the possibility that personnel policies incentivizing veterans to join the executive branch are responsible for veterans' overrepresentation in public jobs. In any event, the modest effects for that cohort - as compared to the comparable findings for the 1950-1952 male cohorts - suggest that even if such a phenomenon took place its substantive import is relatively limited. 
it. To rule out that possibility, we examined whether birthdates randomly called for induction in the Vietnam-Era Selective Service Lotteries (VSSL) appeared excessively in the population of non-sensitive personnel records of the civilian, nondefense and non-postal U.S. executive branch. We found that draft-eligible birthdates did indeed appear with unusually high frequency among male employees, but not among female employees. Our findings dovetail with the notion that exogenously imposed military service increases rates of entering civilian U.S. executive branch employment, thus supporting the hypothesis that wartime mobilization has influenced the contemporary administrative state continually. These results, furthermore, suggest that largescale military mustering in times of war or the maintenance of large peacetime armies may have important long-term consequences on the composition of public and private sector labor markets, as well as the productivity of workers in those labor markets. Research indicates that veterans' high level of entering public employment alters the demographic representation of government workforces (Lewis, 2013); also, empirical studies have debated whether military veterans climb to higher levels of responsibility or pay—surrogates for productivity—at the same rate as nonveterans (Johnson, 2015; Johnson and Walker, 2018). Viewed in light of this study's results, the present findings provide further reason to believe that mobilization policies affect the makeup and performance of the public sector-thus offering more reason to consider those effects in the evaluation of policies aimed at wartime mobilization.

With those implications recognized, some limitations of the present study should be noted. Here we focused on only one slice of the public sector-the U.S. federal, executive branch. With roughly 2.06 million employees, the non-defense and non-postal executive branch of the U.S. federal government is the largest single civilian public sector employer in the United States (U.S. Congressional Research Service, 2019). In comparison, the U.S. federal judicial 
branch employs only 32,711 employees and the legislative branch employs 30,103 employees (U.S. Congressional Research Service, 2019). The non-postal and non-defense executive branch also employs about half of a million more workers than the total number of state and local employees in California, which ranks as the state with the most such workers, but that portion of the federal executive branch would still amount to only $14 \%$ of the $14,617,399$ individuals working in state and local governments across the U.S. (U.S Census Bureau, 2018). Thus, readers should recognize that the results reported here, though comprehensive for one segment of the public sector, do not tell the full story of how the VSSL affected public-sector employment across the U.S.

In fact, if we assume that the treatment effect of Vietnam-Era military service compelled veterans to seek other forms of public service (such as at the state or local level), then the overall impact on labor markets is proportionally greater than what we have shown here. However, given that the draft lottery induced military service into the U.S. Army and not, say, state National Guard units, its treatment may have induced veterans to seek federal employment to a greater extent than local or state-level public sector service. We think future research using the draft lottery is warranted to investigate the treatment effect of military induction on all levels of public-sector employment as well as that in the private sector (particular occupations, job categories, or agencies may disproportionately drive the effects we observe). Likewise, beyond studies of earnings, the impact of draft status on private sector job type is also worthy of study.

A second limitation of this study is our inability, with the present data, to distinguish the mechanism for the treatment effect we observe. While our study design effectively rules out simultaneous selection into the military and civilian public sectors, we cannot discern the nature of the effect. Such overrepresentation in the public sector after military service may stem from 
the preferential hiring of veterans, increased feelings of patriotism, a loss of competitiveness in the private sector due to missing private labor market experience, a sense of entitlement to public sector "spoils" after serving in the military, socialization to organizational structures common across the military and civilian public bureaucracies, or any number of other dynamics. Adjudicating between these mechanisms will further illuminate the findings of the present study, which show a prominent way in which mobilization for war continues to affect the state. 


\section{References}

Angrist, Joshua D. 1990. Lifetime Earnings and the Vietnam Era Draft Lottery: Evidence from Social Security Administrative Records. American Economic Review 80: 313-36.

Angrist, Joshua D., and Stacey H. Chen. 2011. Schooling and the Vietnam-Era GI Bill: Evidence from the Draft Lottery. American Economic Journal: Applied Economics 3: 96-119.

Belman, Dale, and John S. Heywood. 2004. Public Wage Differentials and the Treatment of Occupational Differences. Journal of Policy Analysis and Management 23: 135-52.

Berinsky, Adam J., and Sara Chatfield. 2015. An Empirical Justification for the Use of Draft Lottery Numbers as a Random Treatment in Political Science Research. Political Analysis 23: 449-454.

Conley, Dalton, and Jennifer Heerwig. 2012. The long-term effects of military conscription on mortality: estimates from the Vietnam-era draft lottery. Demography 49: 841-855.

Ferejohn, John, and Frances McCall Rosenbluth. 2017. Forged Through Fire: War, Peace, and the Democratic Bargain. New York: W.W. Norton.

Gifford, Brian. 2006. The Camouflaged Safety Net: The U.S. Armed Forces as Welfare State Institution. Social Politics 13: 372-399.

Gorski, Philip S. 1993. The Protestant Ethic Revisited: Disciplinary Revolution and State Formation in Holland and Prussia. American Journal of Sociology 99: 265-316.

Green, Donald P., Tiffany C. Davenport, and Kolby Hanson. 2018. Are There Long_Term Effects of the Vietnam Draft on Political Attitudes or Behavior? Apparently Not. Journal of Experimental Political Science. https://doi.org/10.1017/XPS.2018.18

Johnson, Tim. 2015. Service after Serving: Does Veterans' Preference Diminish the Quality of the US Federal Service? Journal of Public Administration Research and Theory 25:669-696.

Johnson, Tim. 2017. "The Preferential Hiring of Military Veterans in the United States." In Louis Hicks, Jose E. Coll, Eugenia L. Weiss (eds.), The Civilian Lives of U.S. Veterans: Issues and Identities. Santa Barbara, CA: ABC-CLIO, pp.239-272.

Johnson, Tim, Christopher T. Dawes, Matt McGue, and William G. Iacono. 2018. Numbers Assigned in the Vietnam-Era Selective Service Lotteries Influence the Military Service Decisions of Children Born to Draft-Eligible Men: A Research Note. Armed Forces \& Society 44: 347-367.

Johnson, Tim, and Robert W. Walker. 2018. The Career Advancement of Military Veterans in Recent Cohorts of the U.S. Executive Branch. Public Personnel Management 47: 382-397. 
Kiser, Edgar, and Yong Cai. 2004. Early Chinese Bureaucratization in Comparative Perspective: Reply to Zhao. American Sociological Review 69: 608-612.

Levi, Margaret. 1997. Consent, Dissent, and Patriotism. Cambridge: Cambridge University Press.

Lewis, Gregory B. 2013. The Impact of Veterans' Preference on the Composition and Quality of the Federal Service. Journal of Public Administration Research and Theory 23: 247-265.

Lewis, Gregory B. 2016. "Veterans' Preference and the Federal Service.” In Richard C. Kearney and Jerrell D. Coggburn, (eds.), Public Human Resource Management: Problems and Prospects, 6th ed. Washington, DC: CQ Press, pp. 267-279.

Marshall, T.H. 1950. Citizenship and Social Class. Cambridge: University Press.

Mettler, Suzanne. 2005. Soldiers to Citizens: The G.I. Bill and the Making of the Greatest Generation. New York: Oxford University Press.

Skocpol, Theda. 1992. Protecting Soldiers and Mothers: The Political Origins of Social Policy in the United States. Cambridge, MA: Belknap Press.

Tilly, Charles. 1990. Coercion, Capital, and European States, AD 990-1990. Oxford and Cambridge, MA: Basil Blackwell.

U.S. Census Bureau. 2018. 2017 Government Employment and Payroll Tables. 2017 Census of Governments. Available online: https://www.census.gov/data/tables/2017/econ/apes/annualapes.html.

U.S. Congressional Research Service. 2019. Federal Workforce Statistics Sources: OPM and OMB. Congressional Research Service R43590, Version 9. Washington, D.C.: CRS. 
Figure 1. Distribution of calculated effects across all months of the Central Personnel Data File, June 2011 to March 2016

Male Employees

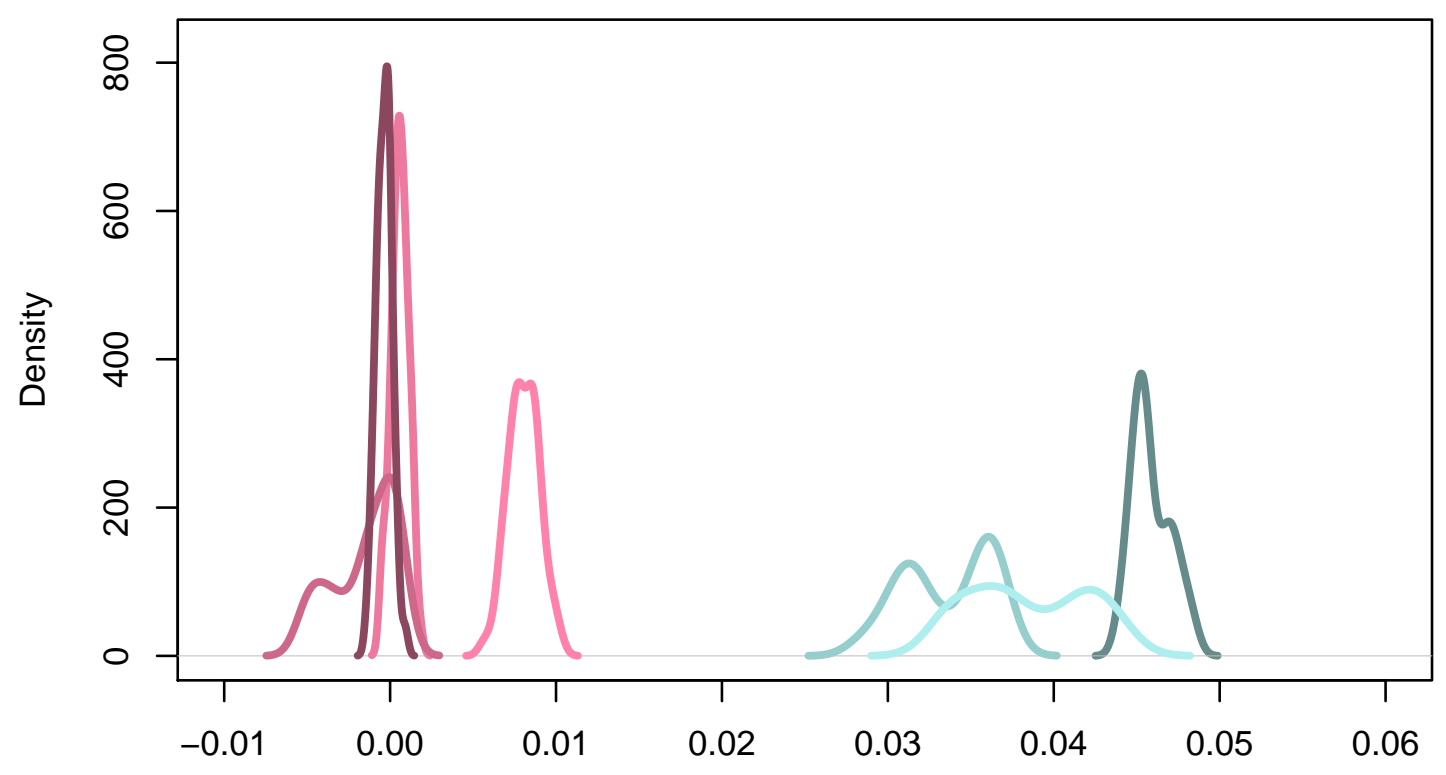

Observed minus Expected Proportion of Male Birthdates Assigned Lottery Numbers Less than the APN $D_{\mathrm{MEt}}=\mathrm{P}_{\mathrm{Mt}}-\mathrm{P}_{\mathrm{Et}}$

Male and Female Employees

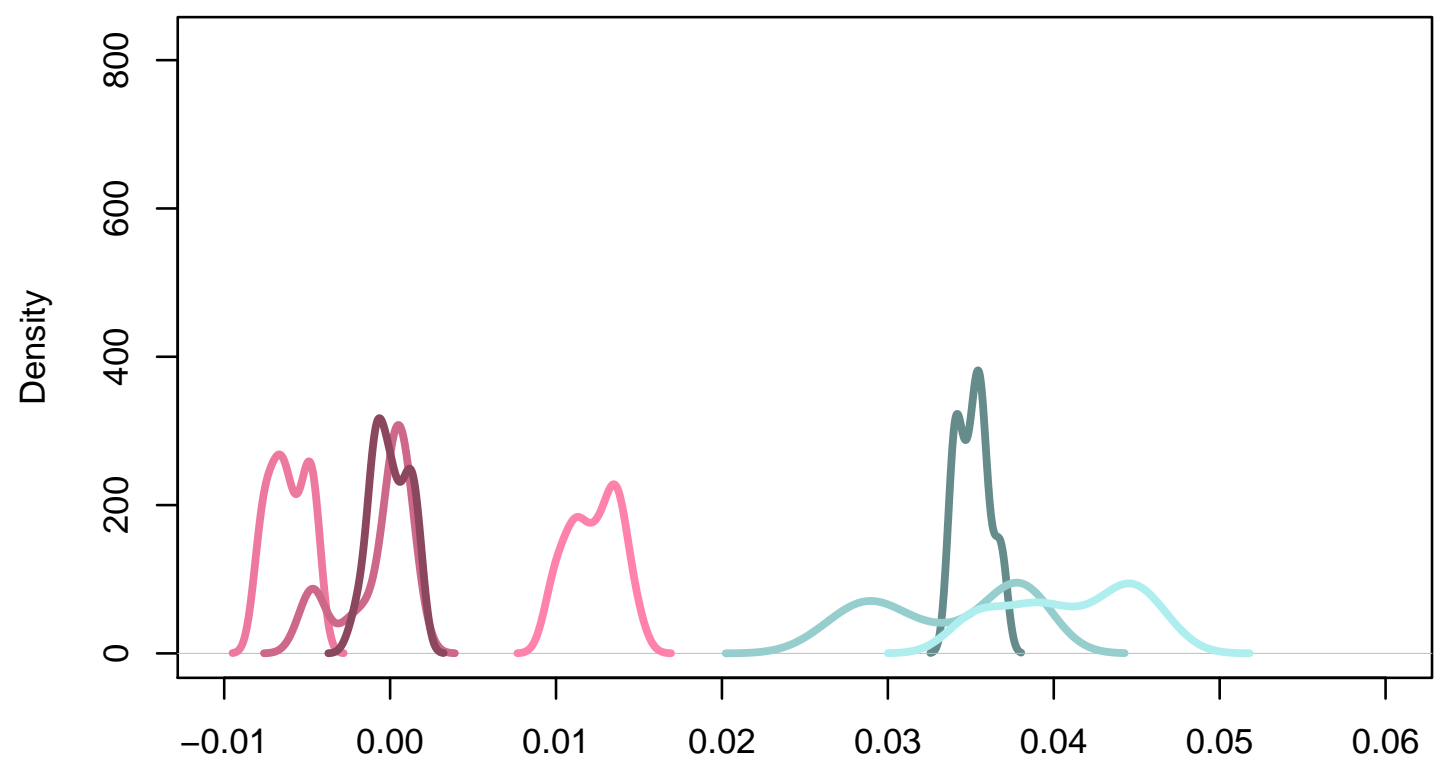

Female Employees

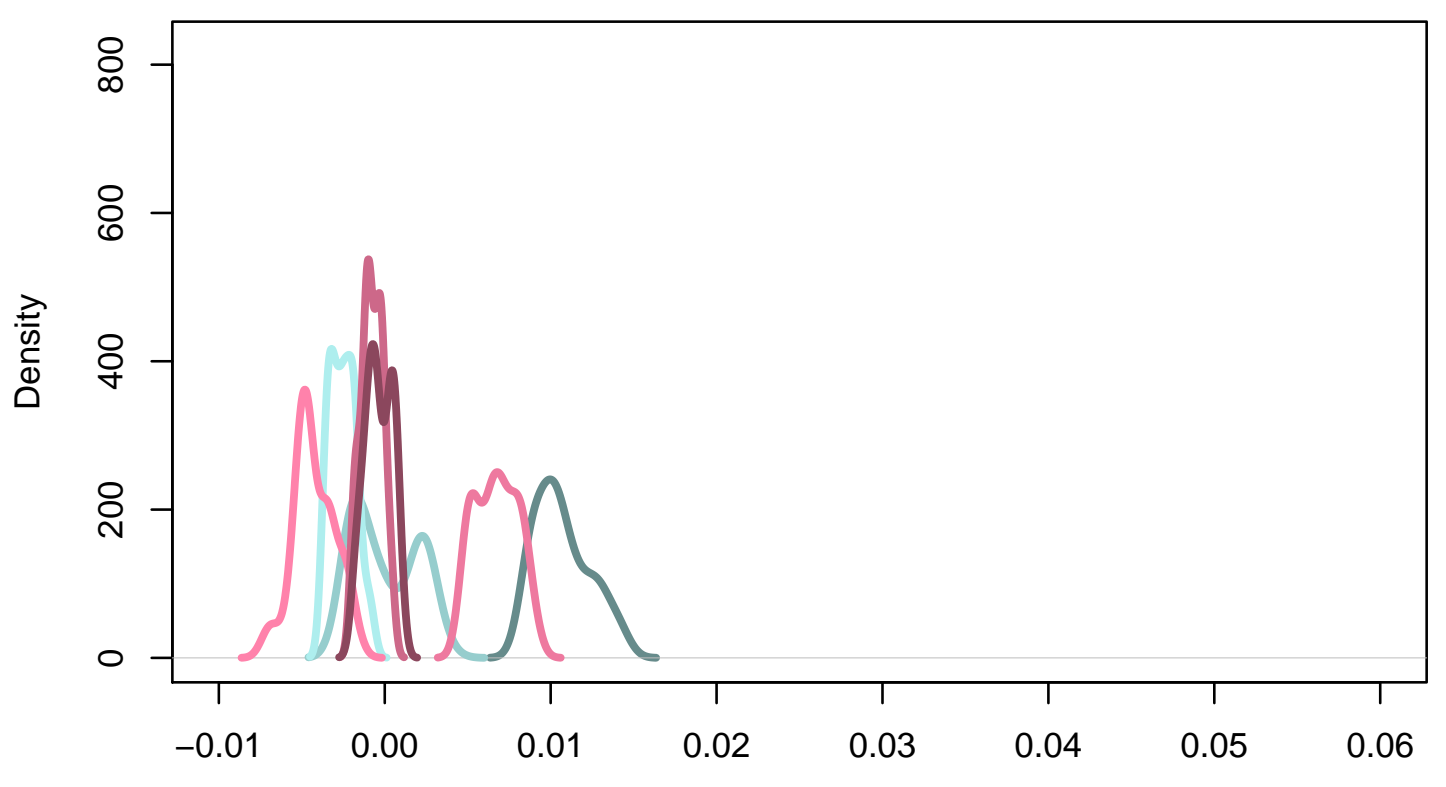

Observed minus Expected Proportion of Female Birthdates Assigned Lottery Numbers Less than the APN $D_{F E t}=P_{F t}-P_{E t}$

Observed Proportion of Male Birthdates minus Observed Proportion of Female Birthdates Assigned Lottery Numbers Less than the APN

$$
\mathrm{D}_{\mathrm{MFt}}=\mathrm{P}_{\mathrm{Mt}}-\mathrm{P}_{\mathrm{Ft}}
$$

1950 Birth Cohort 1951 Birth Cohort 1952 Birth Cohort 1953 Birth Cohort 1954 Birth Cohort 1955 Birth Cohort 1956 Birth Cohort 
Figure 2. Value of lottery numbers and the average number of employees holding them

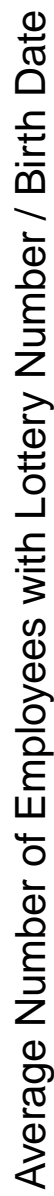

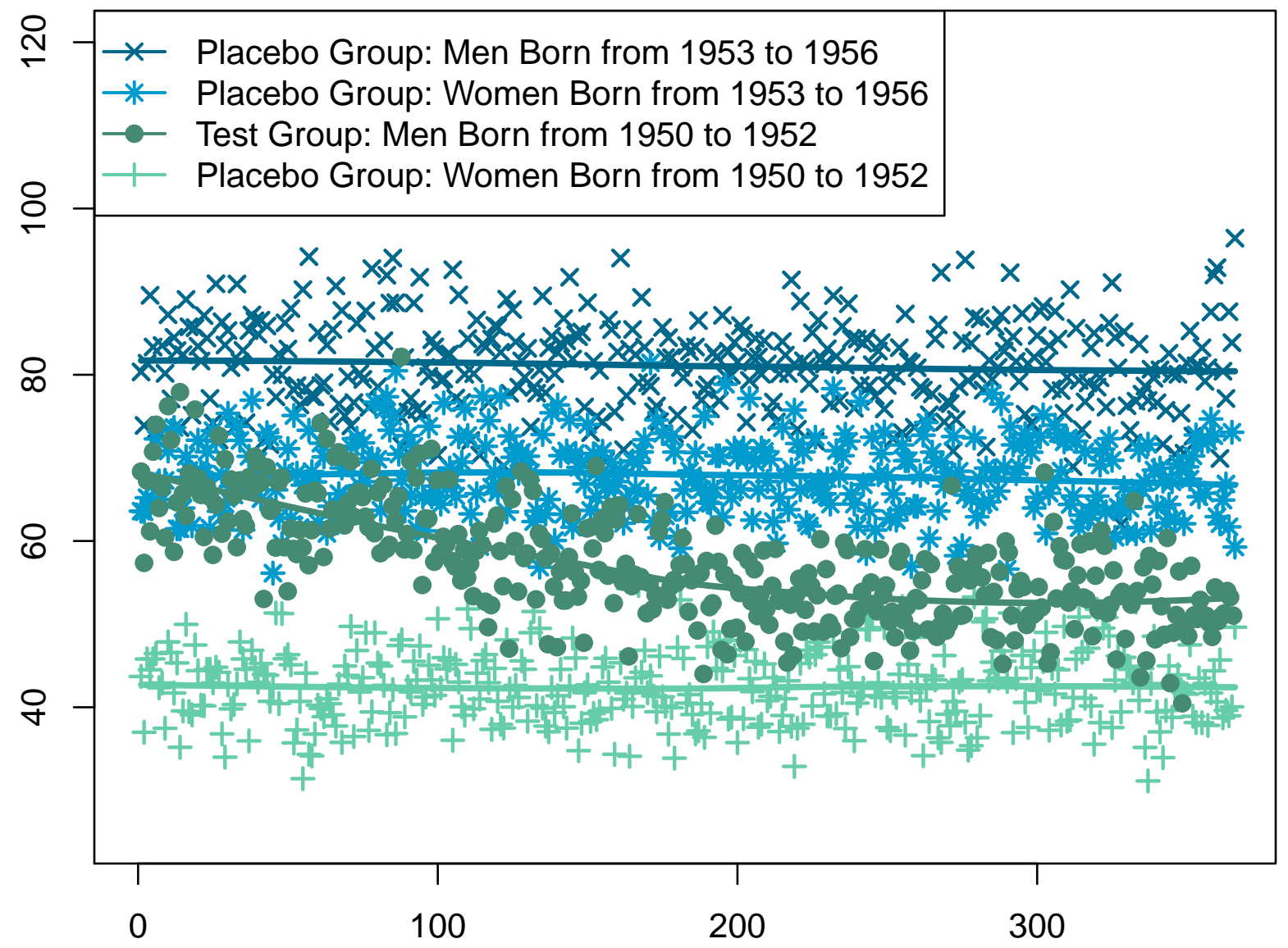

Lottery Number Assigned to Birth Date (RSN) 
Figure 3. Value of lottery numbers and the raw number of employees holding them

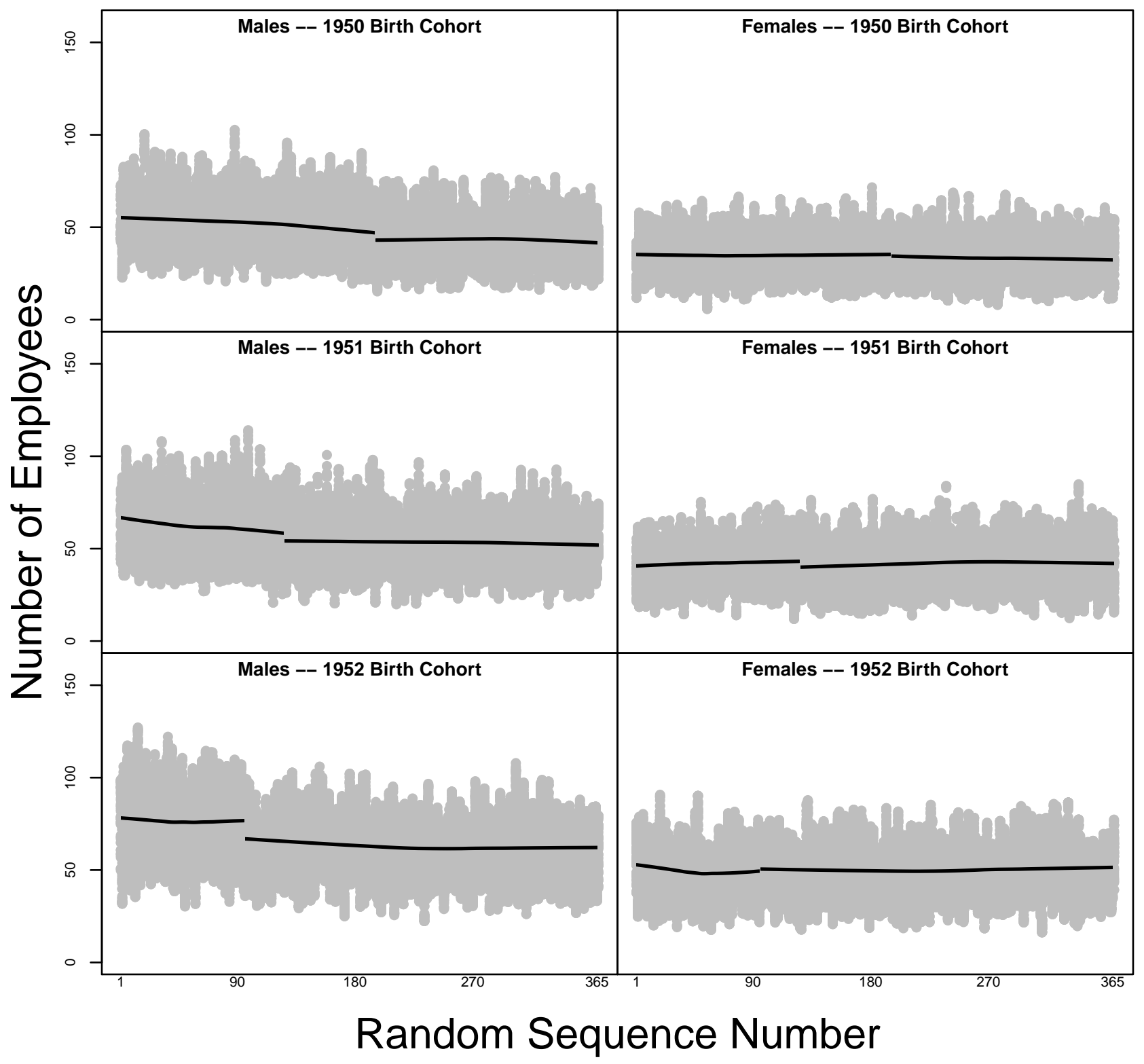


Figure 3. Value of lottery numbers and the raw number of employees holding them

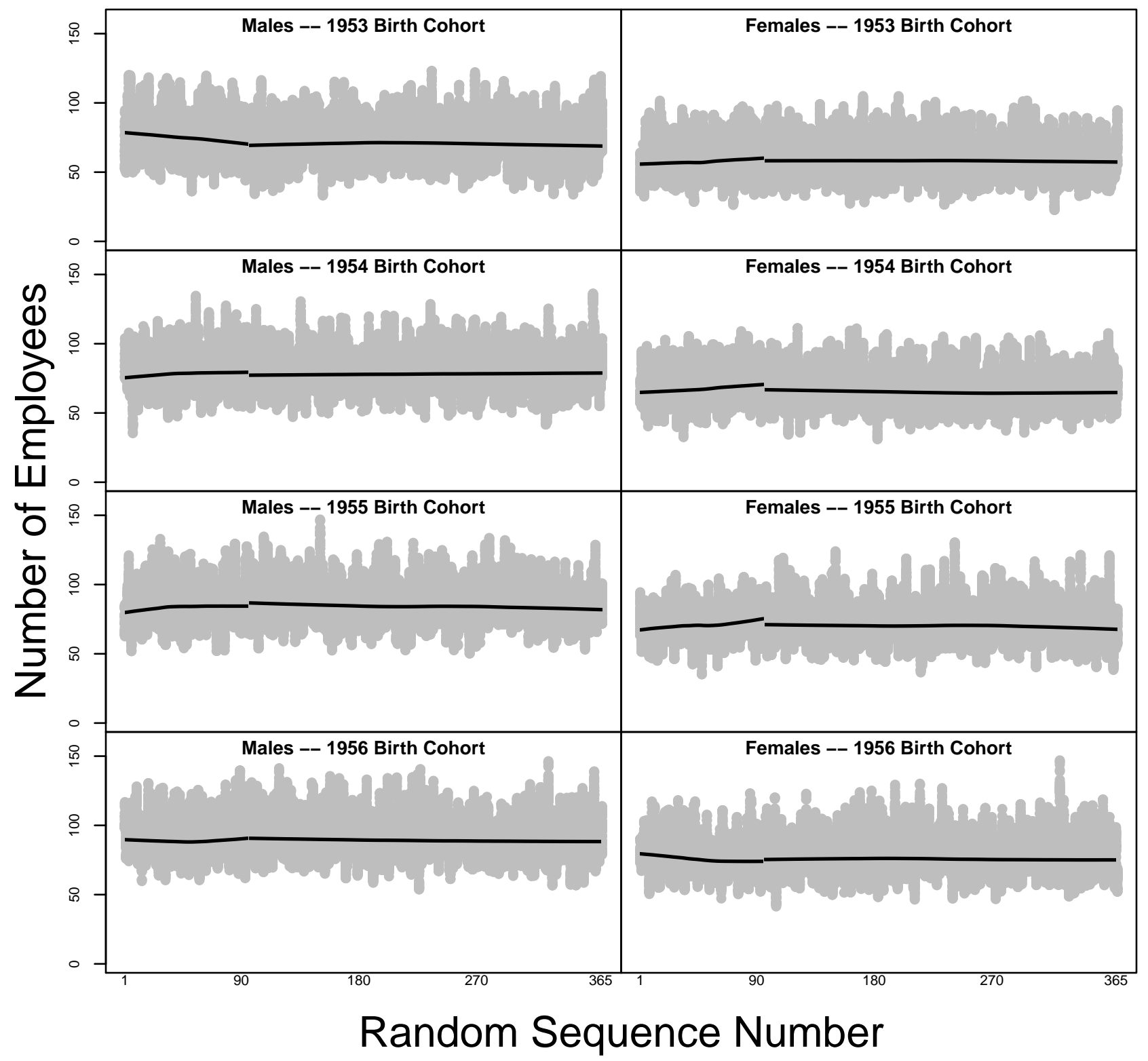

